\title{
LXVII. Comparative tables of the beats of the tempered consonances in M. Kirnberger's and the isotonic or equal temperament systems of tuning; with remarks on the common system used by organ tuners, compared with that of M. Kirnberger
}

Rev. C.J. Smyth

To cite this article: Rev. C. J. Smyth (1810) LXVII. Comparative tables of the beats of the tempered consonances in M. Kirnberger's and the isotonic or equal temperament systems of tuning; with remarks on the common system used by organ tuners, compared with that of M. Kirnberger, Philosophical Magazine Series 1, 35:146, 448-452, DOI: 10.1080/14786441008563121

To link to this article: http://dx.doi.org/10.1080/14786441008563121

Published online: 18 May 2009.

Submit your article to this journal $\sqsubset$

山 Article views: 2

View related articles $\asymp$ 
means. The main spring, or first mover of the system, is thereby, as it were, wound up; and although the several subordinate operations of so complicated a machine cannot be regulated in detail by mere external agency, they must each be performed with greater freedom, in consequence of this general supply of power.

In almost every treatise on the subject of chronical diseases, are to be found numerous instances of the benefit produced by the several modes of gestation which bave been most generally adopted; as riding on horseback, in carriages, sea-voyages, and swinging. And in many cases which might be adduced, it has appeared too clear to admit of a doubt, that the cure of the patient has been oxing solely to the external agitation of his body, which must be allowed, at least, to have had the effect above explained; that of relieving the heart and arteries from a great part of their exertion in propelling the blood, and may therefore have contributed to the cure, by that means only.

The different modes above mentioned are adapted from their nature to different degrees of bodily strength; and if there are cases in which that which appears most eligible may not suit the situation or circumstances of the patient, it cannot be difficult to contrive other means of giving motion, so as least to incommode, and yet to give the greatest relief. A very gentle and long continued, or even incessant motion, may suit some cases better than any more violent and occasional agitation; and in this way, probably, it is, that sea-voyages have sometimes been attended with remarkable advantage.

LXVII. Comparative Tables of the Beats of the Tempered Consonances in M. Kirnberger's and the Isotonic or Equal Temperament Syslems of Tuning; with Remarks on the common System used by Organ Tuners, compared with that of M. Kirnlerger. By the Rev. C. J. Sмхтн, Minor Canon of the Cathedral, Norwich.

$\mathrm{T}$ $T_{\text {He opinions of profound theorists are ever entitled to }}$ attention; but should not be received with implicit faith. If such a man as Sir Isaac Newton was capable of a mistake, so is an Emanuel Bach, or a Kollmann. To the latter gentleman the musical world is under the greatest obligations for reducing the theory of Composition to a degree 
of simplicity, before his writings unknown. But the opinions he has advanced, with respect to the temperament of the musical scale, require that minure investigation and submission to calculation, which, if they had been advanced by a person of less celebrity, might have been passed over in silence.

One of the grand objects at which he appears to aim, is to establish an equal temperament on the piano-forte (that is, that all chords of the same kind shall be alike, as to their degree of imperfection) : to this I raise no objection; the rage for modulation at present exerting its energies, to their utmost possible extent; a rage very fawourable to the talents of those, who have not invention sufficient to produce novel and beautiful melodies, and yet aspire to the character of interesting composers.

I shall first presume to offer a few observations on the unequal temperament of Kirnberger, which Mr. Kollmann supposes " one of the best hitherto known." Not having the happiness to be able to read German, I know not what M. Kirnberger has offered in its behalf; or those important observations which major 'Templehoff (in an Essay in that language published in 1775 , Berlin) is said by Dr. Robison in the Encyc. Brit., art. Temperament, to have made, on Kirnberger's system.

Preferring at all times experiment to theory, I tuned my piano-forte according to Mr. Kollmann's printed directions, with a view to hear the effect of one of " the best unequal temperaments." I camnot speak favourably of the result. I will below subjoin a table of the lealings of the tempered consonances, in order to give those professors who may feel no inclination to submit to the drudgery of calculation, some idea of what the effect of this temperament would be on an organ, where those beatings are most distinctly heard: a formidable host of foes, inimical to correct, and even tolerable tune. It appears to me, in the outset, doubtful whether a tempered system should have any perfect chords (but the octares); as those chords, whenever they are heard, will render the ear less disposed to be pleased with the imperfect harmony which follows.

We will suppose the performer on the organ, to begin with Kimbergerss system in the key of $\mathrm{C}$, answering to the tenor clif; here is a chord absolutely perfect; so also is the chord of $G$, the fifts of the key; bat the chord of the fourth of the key ranks, in point of importance, next to the key-note and its fifth; and here unfortmuately is a chord of which $A$, the major third to $F$, beats 149 times Vol. 35. No. 146. June 1810 : Ff in 
in $15^{\prime \prime}$. From the key of $\mathrm{C}$ a modulation will naturally be expected into the key of $\mathrm{G}$; which modulation will require the dominant of $G$, viz. the chord of $D$ with a major third, fifth, and seventh. Now the $A$ is half a comma too flat, as a fifth above $\mathrm{D}$, and will beat 75 times in $15^{\prime \prime}$. And this we may take, as the first instance of "a very fine variety of perfection." Surely Mr. Kollmam would have been more consistent in the use of terms, if he had said "varieties of imperfection." The next chord which occurs is that of $E$, the fifth of which is perfect, but the major third beats 2.55 in $35^{\prime \prime}$. The chord of $F$ has already been spoken of; proceed we then to examine the chord of Bo; the fifth is perfect, the major third beats 399 . This chord on Eb beats 266 .

Now let us compare this temperament with that upon organs tuned in the usual manner. I do not give the beats in extreme keys, because they are too rapid to be heard as beatings, except in the lowest part of the scale, and have a rough effect, which is more tolerable than beatings not 100 rapid to be perceived as beatings. One chord, viz. that of $A h$ or $G$ kas a peculiar character, (it is called the wolf) the fifth being almost the fifth part of a minor tone too sharp, and the beatings are distinctly heard in the middle and lower part of the scale.

Chords on the Organ, as tuned in the usual Manner. C, G, D, A, and E, good. $B, F_{*}, C_{*}$ and $G_{*}$. The major thirds almost one fourth of a minor tone too sharp, and $\mathrm{Ab}$ (or $\mathrm{G}$ *) has also a fifih almost $F, \mathrm{Bb}$ and $\mathrm{Eb}$, good. one-fifth of a minor tone too sharp, as before observed.

When we hear an organ tuned in this manner, we may consider ourselves at a feast, in which there are dishes of various qualities ; while in M. Kirnberger's feast of exquisite viands, but eight dishes are very palatable, and those who are fond of sour crout and olives, and, like many of our best composers, have uo objection to a slice of wolf, though they would not choose to dine entirely upon that outlandish animal, have an opportunity of gratifying their peculiar palates. Until, therefore, some irrefragable arguments are produced, to prove the superiority of M. Kirnherger's temperament to that in common use, I presume our organbuilders and organ-tuners will, in spite of any charges of obstinacy, ignorance, or policity, continue to tune as their ancestors did before them: as I cannot flatter myself the 
public will ever go to an enormous expense, for many additional pipes, in order that our old and young organists may perform their wonderful feats of modulation (which require as little genius as application) without torturing those who prefer tolerable tune, to the parade of science. Further observations, on mean-tone temperaments, may be offered hereafter.

\section{J. SмYтн.}

M. Kirnberger's Temperament, Beats in $15^{\prime \prime}$.

(The Vibrations communicated by Mr. FAREY.)

\begin{tabular}{|c|c|c|c|c|c|c|c|}
\hline Keys. & Vibrations in $1^{\prime \prime}$ & Sds. & IIIds. & Aths. & Vths. & 6ths. & VIths. \\
\hline c & 480 & & & & & & \\
\hline B & 450 & 0 & 383 & 0 & o & 0 & 383 \\
\hline $\mathrm{Bb}$ & $426 \cdot 6667$ & 474 & 399 & 0 & 0 & 574 & 399 \\
\hline A & $402 \cdot 4922$ & 224 & 153 & 150 & 112 & 299 & 188 \\
\hline$A b$ & 379.2593 & 383 & 355 & 0 & o & 510 & 355 \\
\hline G & 360 & 399 & 0 & o & o & 533 & 0 \\
\hline Gb & $337 \cdot 5$ & 188 & 287 & o & 17 & 0 & 287 \\
\hline F & 320 & 355 & 149 & 0 & 0 & 474 & 300 \\
\hline E & 300 & 0 & 255 & 112 & o & 0 & 255 \\
\hline $\mathrm{E}_{b}$ & $284 \cdot 4444$ & 287 & 266 & 0 & o & 383 & 266 \\
\hline D & 270 & 300 & 0 & 0 & 75 & 399 & 0 \\
\hline Db & 252.8395 & 25.5 & 237 & 17 & 0 & 153 & 237 \\
\hline $\mathrm{C}$ & 240 & 266 & o & o & 0 & 355 & 112 \\
\hline & & 3131 & 2484 & 279 & 204 & 3680 & 2782 \\
\hline & & 2484 & & & & & \\
\hline & & 279 & & & & & \\
\hline & & 204 & & & & & \\
\hline & & $\begin{array}{l}3680 \\
2780\end{array}$ & & & & & \\
\hline & & & & & & & \\
\hline & & 1 & \multicolumn{2}{|c|}{ Sum total } & & & \\
\hline
\end{tabular}


The Isotonic ScAte*, Beats in 15".

(The Vibrations communicated by Mr. Farey.)

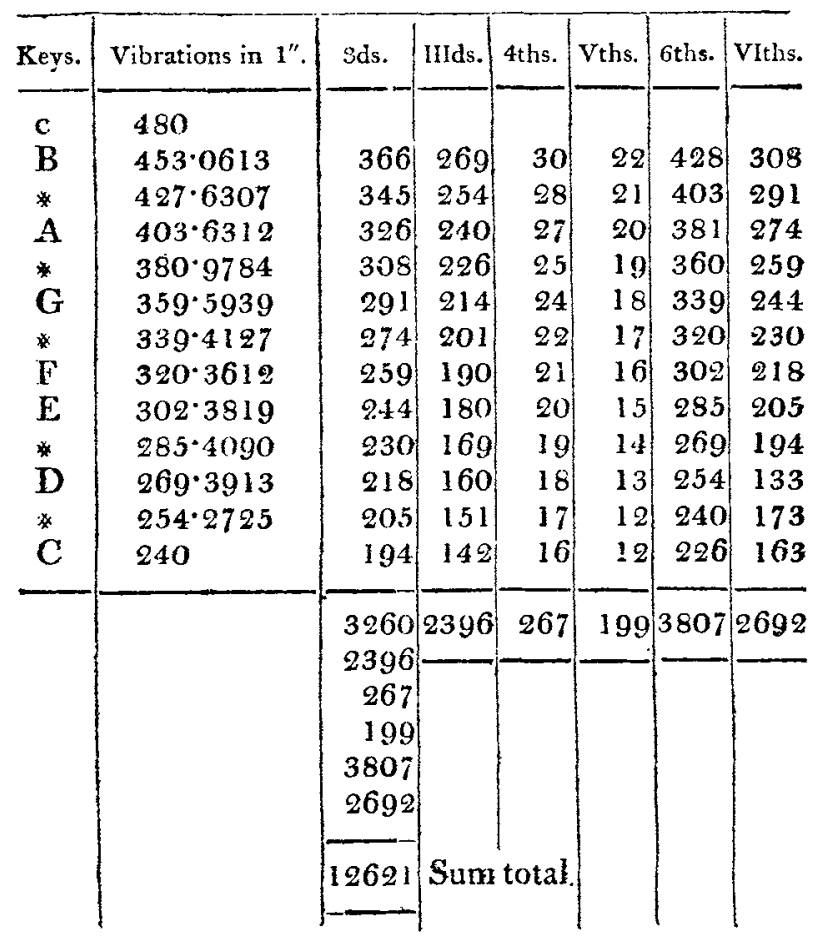

LXVIII. On Crystallography. By M. HaUY. Translated from the last Paris Edition of his Traite de Miréralogie.

[Continued from p. 363.]

GEOMETRICAL CHARACTERS OF ERYSTALS.

16. Forms. Nucleus or primitive form.

$I_{\mathbf{T}}$ is very rare to frod a mineral under its primitive form given immediately by nature, and there is a certain number of species in which this form is known only from the results of mechanical division and by theory. The just measurement of actions susceptible of producing it is only as

* See our xxviith volume, p. 65, and our xxixth volume, p. 347--EDIT. 